\title{
NMR structural analysis of the yeast cytochrome $c$ oxidase subunit Cox13 and its interaction with ATP
}

\author{
Shu Zhou ${ }^{1,2 \dagger}$, Pontus Pettersson ${ }^{1 \dagger}$, Markus L. Björck ${ }^{1 \dagger}$, Hannah Dawitz ${ }^{1}$, Peter Brzezinski ${ }^{1}$, Lena Mäler ${ }^{1 *}$ and
} Pia Ädelroth ${ }^{1 *}$ (i)

\begin{abstract}
Background: Mitochondrial respiration is organized in a series of enzyme complexes in turn forming dynamic supercomplexes. In Saccharomyces cerevisiae (baker's yeast), Cox13 (CoxVla in mammals) is a conserved peripheral subunit of Complex IV (cytochrome c oxidase, CytcO), localized at the interface of dimeric bovine CytcO, which has been implicated in the regulation of the complex.

Results: Here, we report the solution NMR structure of Cox13, which forms a dimer in detergent micelles. Each Cox13 monomer has three short helices (SH), corresponding to disordered regions in X-ray or cryo-EM structures of homologous proteins. Dimer formation is mainly induced by hydrophobic interactions between the transmembrane (TM) helix of each monomer. Furthermore, an analysis of chemical shift changes upon addition of ATP revealed that ATP binds at a conserved region of the $C$ terminus with considerable conformational flexibility.

Conclusions: Together with functional analysis of purified CytcO, we suggest that this ATP interaction is inhibitory of catalytic activity. Our results shed light on the structural flexibility of an important subunit of yeast $\mathrm{CytcO}$ and provide structure-based insight into how ATP could regulate mitochondrial respiration.
\end{abstract}

Keywords: ATP, Membrane protein, NMR, Solution structure

\section{Background}

The mitochondrial electron transport chain (ETC) is comprised of a series of enzyme complexes (I-IV) where electrons are transferred through a series of electron donors and acceptors, coupled to the generation of a proton gradient across the mitochondrial inner membrane. This gradient is used for energy-requiring processes, such as ATP synthesis by Complex V (ATP synthase). Complex IV (cytochrome $c$ oxidase, $\mathrm{Cyt} c \mathrm{O}$ ) is the terminal enzyme of the ETC and catalyzes the reduction of

\footnotetext{
* Correspondence: lena.maler@dbb.su.se; pia.adelroth@dbb.su.se

†Shu Zhou, Pontus Pettersson and Markus L. Björck contributed equally to this work.

${ }^{1}$ Department of Biochemistry and Biophysics, Stockholm University, Stockholm, Sweden

Full list of author information is available at the end of the article
}

oxygen to water coupled to the translocation of protons. $\mathrm{Cyt} c \mathrm{O}$ is comprised of three mitochondrially encoded core subunits and a number of nuclear-encoded small and peripheral subunits (for recent reviews, see $[1,2]$ ). The three core subunits, containing all the redox-active cofactors $-\mathrm{Cu}_{\mathrm{A}}$, heme $a$, and the catalytic site consisting of heme $a_{3}$ and $\mathrm{Cu}_{\mathrm{B}}$-exhibit high conservation throughout many respiring organisms $[3,4]$. The remaining subunits are present only in eukaryotes and their number varies; there are, e.g., ten (or eleven $([5,6])$ additional subunits in Bos taurus and eight (or nine, see [7]) in Saccharomyces (S.) cerevisiae. The function of the nuclear-encoded additional subunits within the complex is poorly understood, but most mitochondrial CytcOs possess homologs of most of them and some of them

(c) The Author(s). 2021 Open Access This article is licensed under a Creative Commons Attribution 4.0 International License, which permits use, sharing, adaptation, distribution and reproduction in any medium or format, as long as you give appropriate credit to the original author(s) and the source, provide a link to the Creative Commons licence, and indicate if changes were made. The images or other third party material in this article are included in the article's Creative Commons. licence, unless indicated otherwise in a credit line to the material. If material is not included in the article's Creative Commons licence and your intended use is not permitted by statutory regulation or exceeds the permitted use, you will need to obtain permission directly from the copyright holder. To view a copy of this licence, visit http://creativecommons.org/licenses/by/4.0/ The Creative Commons Public Domain Dedication waiver (http://creativecommons.org/publicdomain/zero/1.0/) applies to the data made available in this article, unless otherwise stated in a credit line to the data. 
also have isoforms expressed differently depending on, e.g., tissue type [2]. For some of these supernumerary subunits, roles in assembly, stability, and regulation of the complex have been suggested. For instance, subunit IV in mammalian CytcOs, which corresponds to Cox 5 in yeast, has isoforms differently expressed depending on oxygen tension [8] and has been implicated in ATP binding [1] and subunit $\mathrm{Vb}$ (Cox4 in yeast) has a binding site for $\mathrm{Zn}$.

In the crystal structure of the dimeric bovine Complex IV, subunit VIa is located at the dimer interface [9], whereas in the cryo-EM structures of mammalian supercomplexes, it has a peripheral location $[10,11]$. In the mammalian mitochondrial membrane, Complex IV is present (as a monomer) in different forms of supercomplexes as well as on its own in both monomeric and dimeric forms [12]. In S. cerevisiae, the corresponding subunit, Cox13, resolved to a varying degree in the recent cryo-EM structures of the $\mathrm{III}_{2} \mathrm{IV}_{1-2}$ supercomplex $[7,13]$ was confirmed to localize at a peripheral position without contact with the Complex III dimer. In the $S$. cerevisiae mitochondrial membrane, Complex IV is present mostly in a supercomplex with Complex III or as a monomer (see, e.g., $[12,14]$ ), whereas the dimeric form was found (at a low level) in the purified Complex IV preparation [15].

In bovine mitochondria, subunit CoxVIa (the yeast Cox13 homolog) was suggested to house an allosteric ATP binding site at the $\mathrm{N}$ terminus residing in the mitochondrial matrix [16]. Bovine as well as human CoxVIa displays tissue-specific isoforms $[16,17]$ and might therefore be involved in fine-tuning the response of Complex IV to environmental factors.

S. cerevisiae Complex IV, where the nuclear-encoded subunits are amenable to genetic manipulation, can assemble and is active in the absence of Cox13 [18]. Cox13 together with Cox12 has been found to be easily lost from Complex IV and a Cox13-deficient form, found even in wildtype mitochondria [19], is associated with formation of reactive oxygen species [19]. It was shown that the activity of the Cox13-deficient Complex IV has an altered dependence on ATP [20]. Taanman et al. suggested that there are two allosteric ATP binding sites, one of which is present in Cox13, but in contrast to the bovine $\mathrm{Cyt} c \mathrm{O}$, the ATP binding site in yeast was suggested to locate to the C-terminal part of Cox13, residing in the intermembrane space (IMS).

In this study, we investigated the detailed role of $S$. cerevisiae Cox13. For this purpose, we expressed it separately from the Complex IV and determined its structure in detergent micelles using solution NMR. We then used NMR to localize a possible allosteric ATP binding site on Cox 13 and found that residues at the $\mathrm{C}$ terminus of Cox13, which resides in the intermembrane space, interact with ATP. Based on our data, we modeled possible ways to achieve this allosteric site. We also studied the catalytic activity of $\mathrm{Cyt} c \mathrm{O}$ from both wildtype and a Cox13-deletion strain of S. cerevisiae, which showed altered dependence on ATP. Possible mechanisms for the ATP effect on $\mathrm{Cyt} c \mathrm{O}$ activity mediated by $\mathrm{Cox} 13$ are discussed. This study provides new structure-based insight into the function of Cox13 and the regulation of mitochondrial respiration.

\section{Results \\ Characterization of the refolded Cox 13 protein}

In this study, Cox13, with a predicted mass of $15 \mathrm{kDa}$, was recombinantly overexpressed in Escherichia coli. Inclusion-body protein precipitate was refolded in the detergent dodecylphosphocholine (DPC). From a sizeexclusion column (SEC), the Cox13-DPC complex eluted in a single peak (Additional file 1: Figure S1A), indicating that it was present in a single oligomeric state with an apparent mass of 55-60 kDa (see calibration inset in Additional file 1: Figure S1A). This size is consistent with a dimer of Cox13 $(2 \times 15 \mathrm{kDa})$ in a DPC micelle $(\sim 25 \mathrm{kDa}$ [21]). The expected molecular mass and purity were confirmed by SDS-PAGE, where the Cox13 monomer runs at an apparent mass of $16 \mathrm{kDa}$ and a fraction consistent with a dimer was also observed (Additional file 1: Figure S1B). Far-UV circular dichroism (CD) spectroscopy revealed that $\alpha$-helix is the dominant structural element in refolded Cox13 protein (Additional file 1: Figure S1C). The Cox13DPC complex was further analyzed by a two-dimensional (2D) heteronuclear single quantum correlation (HSQC) NMR experiment, and was found to have good spectral characteristics, and the expected dispersion of resonances typical for an alpha-helical protein [22, 23]. A transverse relaxation optimized spectroscopy (TROSY) type ${ }^{15} \mathrm{~N}-{ }^{1} \mathrm{H}$ HSQC spectrum recorded at $900 \mathrm{MHz}$ demonstrated that conducting solution NMR-based structural studies on Cox13 was feasible (Fig. 1).

\section{NMR resonance assignment}

The backbone chemical shifts assignment of Cox13 was completed to $93 \%$ using a combination of six TROSYtype heteronuclear triple-resonance experiments with a $\left[\mathrm{U}-{ }^{15} \mathrm{~N},{ }^{13} \mathrm{C}\right]$-labeled sample (Additional file 1: Figure S2). The secondary structure of Cox13 in DPC micelles was determined using backbone secondary chemical shifts [24], which clearly demonstrate that Cox13 contains four $\alpha$-helices (Fig. 1c): $\alpha 1$ (A29-A39), $\alpha 2$ (T48E79), $\alpha 3$ (P93-F106), and $\alpha 4$ (D112-R123), which are separated by regions lacking well-defined secondary structure. Resonance assignments were extended using the combination of side-chain correlation experiments and nuclear Overhauser effect (NOE) experiments on differently labeled samples. Specifically, the assignment 

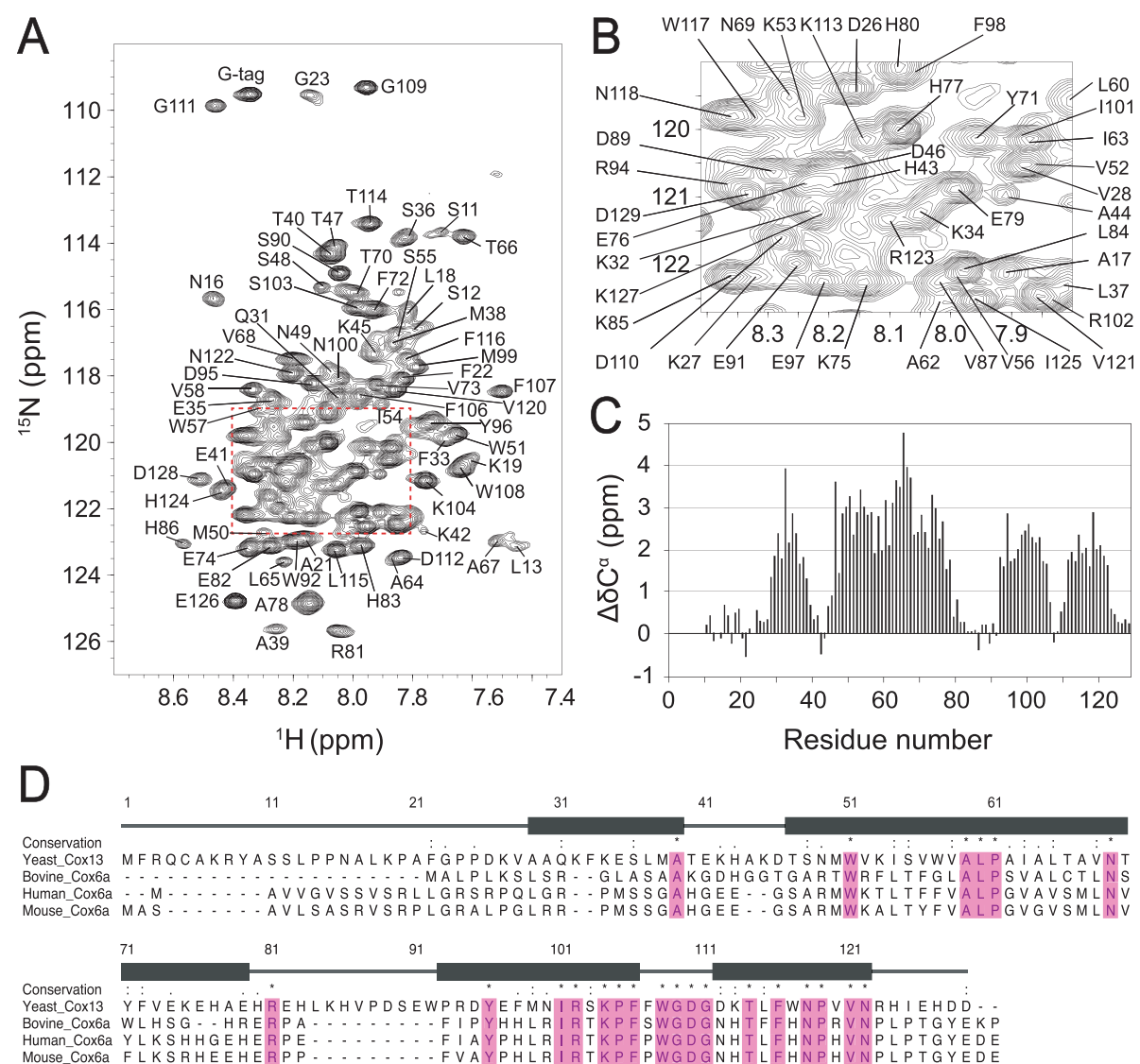

Fig. 1 Backbone chemical shift assignment of Cox13 in DPC micelles. a $900 \mathrm{MHz} 2 \mathrm{D}{ }^{1} \mathrm{H}^{-15} \mathrm{~N}$ TROSY-HSQC spectrum of $0.4 \mathrm{mM}\left[{ }^{15} \mathrm{~N}\right.$, $\left.{ }^{13} \mathrm{C}\right]-$ labeled Cox13 in $20 \mathrm{mM} \mathrm{NaP}$ i pH 6.5, $50 \mathrm{mM} \mathrm{L-Arg,} 50 \mathrm{mM} \mathrm{L-Glu}, 1 \mathrm{mM}$ DTT, and $30 \mathrm{mM} \mathrm{DPC}$ recorded at $40^{\circ} \mathrm{C}$. The assignment of each peak is given with residue one-letter code and sequence number. $\mathbf{b}$ For clarity, the central region of the spectrum is enlarged. c The Ca secondary chemical shifts of Cox13 in DPC micelles plotted versus the amino acid sequence. Consecutive positive secondary chemical shifts indicate a-helical secondary structure. $\mathbf{d}$ Protein sequence alignment for Cox13 in selected homologs. Positions of experimentally determined a-helices are indicated above the alignment. Pink shading indicates conserved residues across the homologs

of approximately $79 \%$ of side-chain resonances was achieved (Additional file 1: Figure S3). The NOE crosspeak assignments were obtained by an iterative procedure using a combination of manual and automatic approaches. A total of 1324 intramolecular NOE distance restraints were extracted from the ${ }^{15} \mathrm{~N}$ and ${ }^{13} \mathrm{C}$-edited NOESY-HSQC spectra. Moreover, using a mixed sample with $50 \%\left[\mathrm{U}_{-}{ }^{15} \mathrm{~N},{ }^{13} \mathrm{C}\right]$-labeled protein and $50 \%$ unlabeled protein, ${ }^{15} \mathrm{~N},{ }^{13} \mathrm{C}$-filtered/edited NOESY experiments were carried out to detect NOE cross-peaks that are due to intermolecular interactions [25] (Additional file 1: Figure S4). The presence of intermolecular NOE cross-peaks in combination with the SEC profile indicated that Cox13 forms a dimer under our experimental conditions. Altogether, the collected data allowed us to determine a well-defined Cox13 dimer structure.

\section{Solution structure of Cox13 dimer in DPC micelles}

A final ensemble of the 15 lowest-energy structures calculated using the program CNS [26] representing the
Cox13 dimer in DPC micelles is depicted in Fig. 2a. Summaries of the experimental constraints and structural statistics are given in the supplementary information (Additional file 1: Tables S1 and S2). Overall, the solution structure of the Cox13 dimer is characterized by the dimeric transmembrane (TM) entity, composed of the TM helix from each monomer, forming a two-helix bundle (Fig. 2b). Apart from the TM region $(\alpha 2)$, each Cox13 monomer structure also contains three short helices, the $\alpha 1$-helix at the $\mathrm{N}$ terminus, and the $\alpha 3$ - and $\alpha 4$-helices at the $\mathrm{C}$ terminus. The helices are connected by short- or medium-length loops. These helices do not have welldefined positions in the structure (Fig. 2), but a few distance restraints between the $\alpha 3$ and $\alpha 4$ helices were found, indicating that they interact, at least transiently. The high helicity of the Cox13 dimer structure is consistent with the $\mathrm{CD}$ spectrum and secondary chemical shift analysis (Additional file 1: Figure S1 and Fig. 1c). 
A

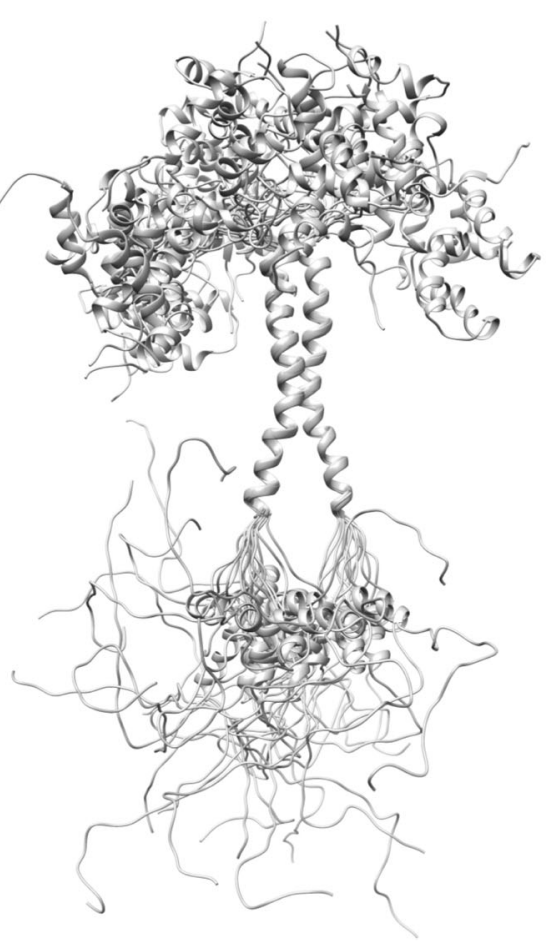

C

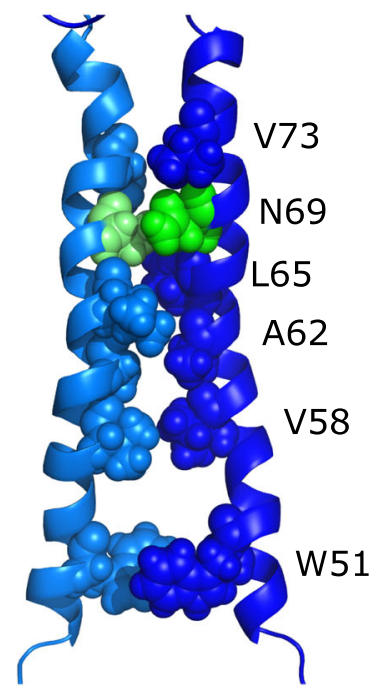

B

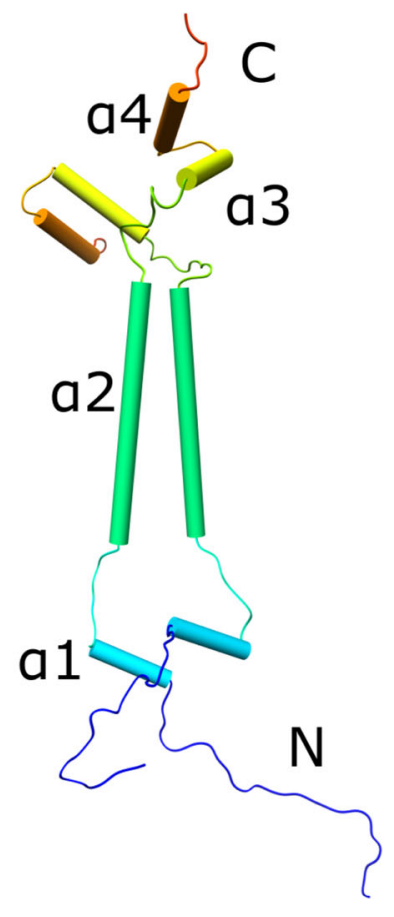

D

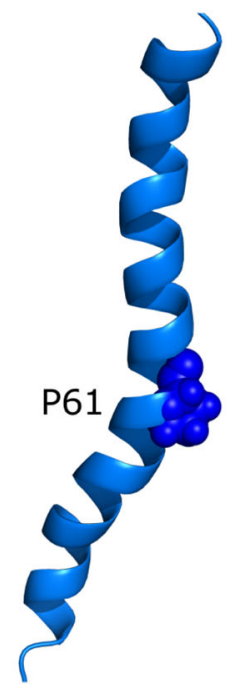

Fig. 2 Solution structure of Cox13 in DPC micelles. a Backbone ribbon trace of the 15 lowest-energy structures determined by solution-state NMR. $\mathbf{b}$ Cylindrical representation of the Cox13 dimer structure. The four helices of a monomer are shown (see labels). c Clusters of stabilizing nonpolar interactions (shown are those between W51, V58, A62, L65, and V73 from each helix) at the dimer interface, and the polar interaction between the two N69, shown in green. $\mathbf{d}$ Residue P61 inducing the kink in the TM helix is shown in sphere representation

The Cox13 dimer interface is well-defined from intermolecular NOEs and its dimeric TM core is mainly formed by hydrophobic interactions, which include the residues W51, V58, A62, L65, T66, F72, and V73 (Fig. 2c and Additional file 1: Table S2). In addition, an interaction between $\mathrm{N} 69$ in each monomer appears to stabilize the dimer formation. Notably, residue P61 induces a kink in the TM helix (Fig. 2d), which is 
presumably involved in forming the bow-shaped structure observed for the Cox13 in the full $\mathrm{III}_{2} \mathrm{IV}_{2}$ supercomplex structure [7].

In summary, the solution structure of the Cox13 dimer in DPC micelles comprises a well-defined TM bundle induced by the interaction between the TM $\alpha 2$-helix from each monomer, while the positions of the other helices are less defined. NOEs were, however, found between the $\alpha 3$ and $\alpha 4$ helices indicating an interaction between them.

To better understand the position of Cox13 in micelles, we carried out paramagnetic relaxation enhancement (PRE) experiments by recording 2D TROSY-HSQC spectra in the presence of either the detergent-soluble 16doxyl stearic acid (16-DSA) or water-soluble gadodiamide. From data obtained with the latter compound, the most affected (and thus solvent-exposed) regions of Cox13 is the random coil following the TM helix, as well as the Cterminal unstructured residues (Additional file 1: Figure S5). In comparison, the $\alpha 3$ and $\alpha 4$ helices have slightly higher intensity ratios than the flanking loops and are thus only partially solvent-exposed. 16-DSA data supports the gadodiamide results for the aforementioned regions by showing opposite trends in intensity ratios. As expected, detergent-embedded 16-DSA has a large effect on the residues of the transmembrane helix, but also interestingly on some residues in the $\mathrm{N}$-terminal loop and on the $\alpha 3$ and $\alpha 4$ helices. The results thus indicate an interaction of $\alpha 3$ and $\alpha 4$ with detergent in the micelle-water interface. Together with gadodiamide's overall modest attenuation of the signal intensity for the $\mathrm{N}$-terminal loop and $\alpha 1$ helix, the results indicate that large parts of Cox13 fold back on and interact with the micelle. We conclude that the interaction with detergent contributes to the stability of the non-transmembrane helices $\alpha 1, \alpha 3$, and $\alpha 4$.

\section{Comparisons to Cox13 and homologs in full CytcO structures}

The Cox13 subunit was recently resolved in a cryo-EM structure of the $\mathrm{II}_{2} \mathrm{IV}_{2}$ supercomplex from $S$. cerevisiae
[7], which shows that it is localized at a peripheral position without contact with the Complex III dimer (Fig. 3a). A comparison of our NMR structure to the Cox13 structure in the $\mathrm{III}_{2} \mathrm{IV}_{2}$ complex (Fig. 3b) shows a similar overall topology, with a relatively well-aligned TM region, but significant differences in the overall structure. The largest differences are in the soluble domains, where the region occupying the intermembrane space (IMS) is mostly disordered in the supercomplex, whereas it folds into two short helices in our NMR structure. However, this is a very flexible region of the protein, which in the $\mathrm{III}_{2} \mathrm{IV}_{2}$ complex makes contacts with Cox3 and Cox12, discussed further below (and see [27]). Yeast Cox13 is in part homologous with bovine subunit VIa and is similarly positioned in relation to other $\mathrm{Cyt} c \mathrm{O}$ subunits. In the crystal structure of the bovine Complex IV dimer, subunit VIa is located at the dimer interface [9], but there are no major differences to the subunit VIa structure in the monomeric $\mathrm{CytcO}$ form [28]. Comparing yeast Cox13 to the bovine subunit VIa (Fig. 3b), the largest differences are seen at the matrix-facing $\mathrm{N}$-terminal region, where Cox13 has an organism-specific extension which is not present in subunit VIa.

In the yeast cryo-EM supercomplex structure, the Cox13 TM helix is significantly longer than in our NMR structure, and the TM region makes contact with Cox3, and the recently resolved (for specific conditions) respiratory supercomplex factor 2 (Rcf2) [27]. This applies to some of the residues that form the dimer interaction surface in our NMR structure (Fig. 2c), e.g., N69 and V73, which are in contact with Cox3, while V58 and W51 interact with Rcf2. It is interesting to note that the Rcf2 protein, which has been suggested to regulate supercomplex formation and $\mathrm{Cyt} c \mathrm{O}$ activity [29-31], thereby could influence the propensity for Cox13 to induce dimerization of the $\mathrm{Cyt} c \mathrm{O}$, which then could lead to a "string" of supercomplexes, as suggested earlier [32].

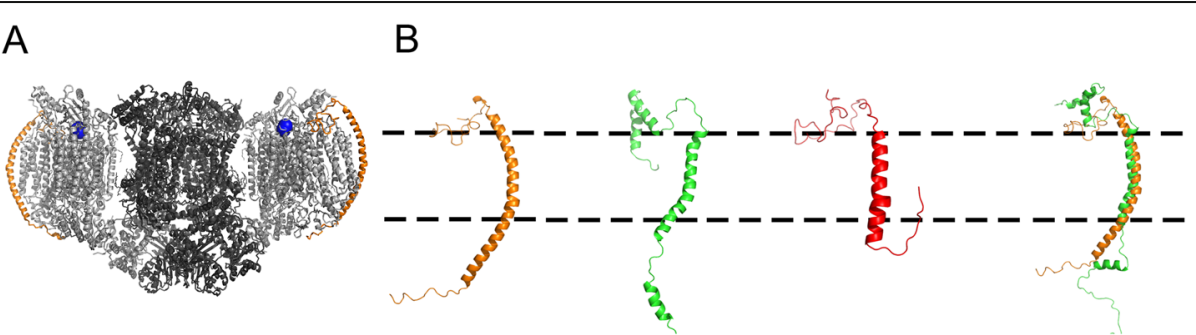

Fig. 3 A comparison of the NMR structure of Cox13 from S. cerevisiae, the cryo-EM structure and the crystal structure of its Bos taurus homologous subunit Vla. a. The cryo-EM structure of the $\mathrm{S}$. cerevisiae III $\mathrm{IV}_{2}$ supercomplex (PDB ID: $6 \mathrm{HU9}$ [7]). The Complex IV monomers are marked in light gray, the Complex III dimer in dark gray, the Complex IV electron entry site $\mathrm{Cu}_{\mathrm{A}}$ as blue spheres (the size is exaggerated to emphasize the $\mathrm{Cu}$ ), and $\mathrm{Cox} 13$ in orange. b A structural comparison of Cox13 from three different sources. The Cox13 from the $\mathrm{II}_{2} \mathrm{IV}{ }_{2} \mathrm{~S}$. cerevisiae complex in orange, one of the Cox 13 monomers in the NMR (dimer) structure in green, and the B. taurus subunit Vla (from PDB ID: 10cc [9]) in red. On the right, the NMR structure of Cox13 is aligned with the same subunit from the cryo-EM structure. The approximate location of the membrane is marked by dashed lines 


\section{Influence of nucleotides on the Saccharomyces cerevisiae Cytco catalytic activity}

For both yeast and bovine $\mathrm{Cyt} c \mathrm{O}, \mathrm{Cox} 13$ (or equivalent) has been suggested to house an allosteric ATP binding site, but at different locations; yeast Cox13 was proposed to house such a site in the IMS [20] whereas in mammalian (bovine) mitochondria, subunit CoxVIa (equivalent to Cox13), was suggested to contain an allosteric nucleotidebinding site at the matrix-facing $\mathrm{N}$ terminus [16].

We purified wildtype $S$. cerevisiae $\mathrm{Cyt} c \mathrm{O}$ with an engineered His-tag on Cox13 to ensure the presence of the subunit (as Complex IV in yeast shows a fraction lacking Cox13 [19]). We also purified the Cox13 $\Delta-\mathrm{Cyt} \mathrm{O}$ (with a Flag-tag on Cox6) in order to assess the influence of the Cox13 subunit on catalytic turnover. We observed no significant effect on the maximum catalytic activity of $\mathrm{Cyt} c \mathrm{O}$ in the absence of Cox13, similar to previous results [20], but the relative activity (between wildtype and Cox13 $\Delta$-CytcO) varied between preparations and with buffer conditions (Additional file 1: Figure S6). ADP had small stimulatory effects for both variants. High phosphate concentrations had a small stimulatory effect in wildtype $\mathrm{Cyt} c \mathrm{O}$, which was increased in $\operatorname{Cox} 13 \Delta-\mathrm{Cyt} c \mathrm{O}$ (Additional file 1: Figure S6). Addition of ATP also increased turnover activity in both wildtype and the Cox13 $\Delta-$ CytcO (Additional file 1: Figure S6), and tentative fits indicate that ATP binds less tight (with tentative $K_{\mathrm{d}}$ in the $\mathrm{mM}$ range, qualitatively similar to a previous study [20]) and with a higher maximum activity in Cox13 $\Delta-$-Cyt $c \mathrm{O}$ (Additional file 1: Figure S6BC). These (and previous [20]) data indicate a complex behavior with more than one ATP binding site on $\mathrm{Cyt} c \mathrm{O}$. In the previous study [20], the results were interpreted in terms of two regulatory ATP binding sites in $\mathrm{Cyt} C \mathrm{O}$, where one is stimulatory and one is inhibitory and located on Cox13.

The data presented above were not easily interpreted, and in the bovine $\mathrm{CytcO}$, it has been shown that the interaction between the electron donor cyt. $c$ and $\mathrm{Cyt} c \mathrm{O}$ is highly dependent on the presence of anions, including ATP and phosphate [33, 34], which could complicate titrations such as those described above. Therefore, we monitored the $\mathrm{Cyt} c \mathrm{O}$ activity as a function of added yeast cyt. $c$ in both the absence and presence of $5 \mathrm{mM}$ ATP using a low- $P_{i}$ buffer for both the wildtype and the Cox13 $\Delta$-CytcO (Fig. 4 and Additional file 1: Figure S7). In the wildtype CytcO, we fitted the data to two $K_{\mathrm{m}} \mathrm{s}$ for cyt. $c$ with values of $1.3 \pm 0.6 \mu \mathrm{M}$ and $20 \pm 10 \mu \mathrm{M}$ (Fig. $4 \mathrm{a}$ ), consistent with a previous study that also found two $K_{\mathrm{m}} \mathrm{s}$ ([35], but see also [36]). In the Cox13 $\Delta-\mathrm{Cyt} c \mathrm{O}$, the higher $K_{\mathrm{m}}$ interaction with cyt. $c$ is very similar, i.e., $20 \pm$ $10 \mu \mathrm{M}$, while the lower $K_{\mathrm{m}}$ is lowered to $0.2 \pm 0.1 \mu \mathrm{M}$. In the presence of $5 \mathrm{mM}$ ATP, there are two clear effects in the wildtype $\mathrm{Cyt} c \mathrm{O}$; first the low $K_{\mathrm{m}}$ cyt. $c$ binding site

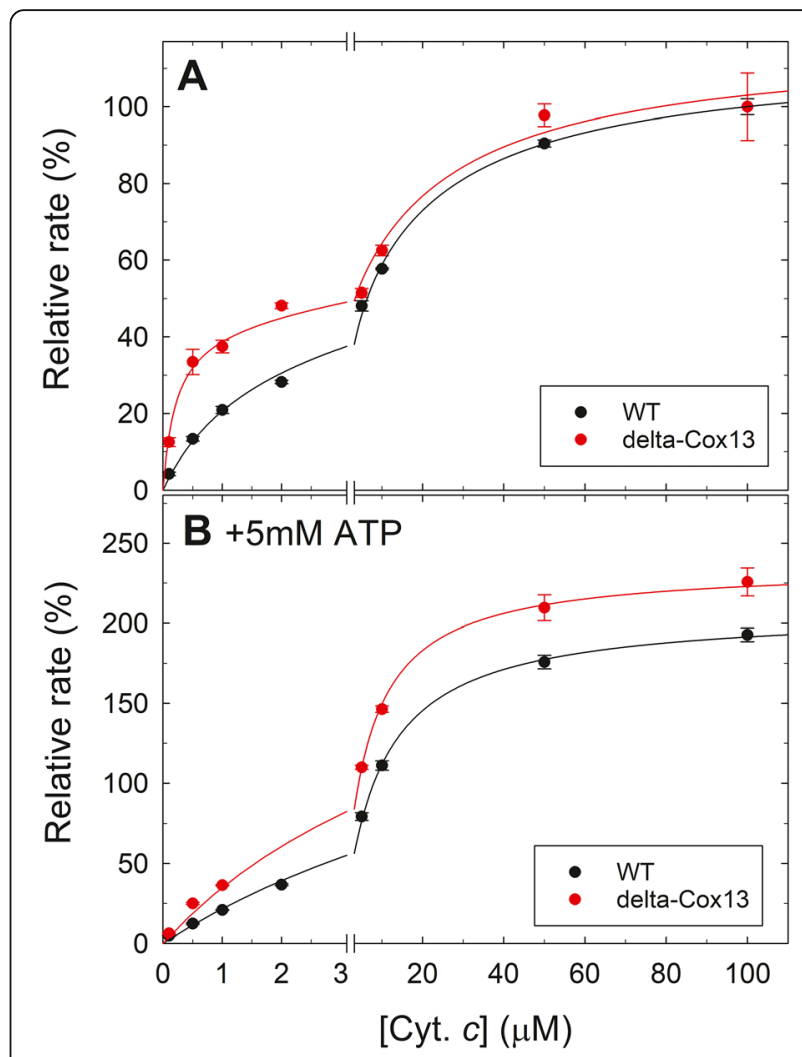

Fig. 4 Turnover rate of wildtype and $\operatorname{Cox} 13 \Delta-\mathrm{CytcO}$ as a function of added yeast cyt. $c$ in the absence (a) and presence (b) of 5 mM ATP. The turnover rate is expressed as relative to the maximum rate achieved (in $\mathrm{e}^{-/ \mathrm{s}}$ ) at $100 \mu \mathrm{M}$ cyt. $\mathrm{c}$ in the absence of additions for both the wildtype and Cox13 $\Delta$-CytcO. For original data, see Additional file 1: Figure S7 and Additional file 2. Data points shown are averages and error bars are standard deviations $(n=3)$. In $\mathbf{a}$, the lines shown are fits to two hyperbolic functions with two $K_{\mathrm{m}} \mathrm{s}$ as follows: Wildtype (black line): $V^{1}: 40 \pm 10 \%, K_{m}{ }^{1}: 1.3 \pm 0.6 \mu \mathrm{M}, V^{2}: 70 \pm$ $10 \%, K_{m}{ }^{2}: 20 \pm 10 \mu \mathrm{M}$. Cox $13 \Delta$-CytcO (red line) $V^{1}: 43 \pm 7 \%, K_{m}{ }^{1}: 0.2 \pm$ $0.1 \mu \mathrm{M} V^{2}: 74 \pm 7 \%, K_{m}{ }^{2}: 20 \pm 10 \mu \mathrm{M}$. In $\mathbf{b}$, the lines are fits to a simple Michaelis-Menten equation (one $K_{\mathrm{m}}$ ): for wildtype (black line) with $\mathrm{V}$ : $208 \pm 2 \%, K_{\mathrm{m}}: 8.6 \pm 0.3 \mu \mathrm{M}$ and for Cox13 $13-\mathrm{CytcO}$ (red line): $236 \pm 3 \%$, $K_{\mathrm{m}}: 5.8 \pm 0.3 \mu \mathrm{M}$. Experimental conditions: $25 \mathrm{mM} \mathrm{KP}$ pH 7.0, 0.035\% DDM, $10 \mathrm{mM}$ ascorbate, and $100 \mu \mathrm{M}$ TMPD

is clearly inhibited (or lost) (similar to the effect observed in bovine $\mathrm{Cyt} c \mathrm{O}$ [33]), and the data can be fitted with only one $K_{\mathrm{m}}$ of $8.6 \pm 0.3 \mu \mathrm{M}$ (Fig. $4 \mathrm{~b}$ and S7). Moreover, the overall maximum activity is stimulated to $208 \pm$ $2 \%$ (Fig. 4b). In Cox $13 \Delta-$ CytcO in the presence of $5 \mathrm{mM}$ ATP, the low $K_{\mathrm{m}}$ interaction with cyt. $c$ is similarly lost with only one $K_{\mathrm{m}}$ at $5.8 \pm 0.3 \mu \mathrm{M}$ (Fig. 4b). Also here, the maximum activity is increased, by a larger factor to $236 \pm$ $3 \%$. Our data shows that the overall affinity for cyt. $c$ is lowered in the presence of ATP in both wildtype and Cox13 $\Delta$-CytcO, but that the increase in the maximum rate is higher in Cox13 $\Delta$ - than in wildtype CytcO. The stimulation of activity in the presence of phosphate is

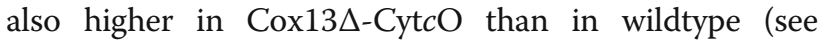


Additional file 1: Figure S6A). It is clear that there are several effects of ATP binding to $\mathrm{Cyt} c \mathrm{O}$ and that removal of the Cox13 subunit impacts at least one of these effects; the maximum stimulation of activity. However, the removal of Cox13 has complex effects on the CytcO activity, discussed further below. There is a difference between our results for the effect of ATP on yeast $\mathrm{Cyt} c \mathrm{O} /$ cyt. $c$ interactions and those obtained for the bovine (or horse) CytcO/cyt. $c$ interactions where ATP more clearly inhibits CytcO activity at low cyt. $c[33,34]$. The reason for this difference is presently unknown, but could be related to the observation that in addition to binding CytcO, ATP binds and affects also horse cyt. $c$ (see e.g. [37]), something that was suggested to not occur in yeast cyt. $c$ [38].

\section{Interaction of Cox13 with ATP and ADP}

We addressed the question of whether or not ATP binds to Cox13 by NMR and CD titration experiments. We first studied ATP/Cox13 interaction by $\mathrm{CD}$ up to a molar ratio of $\sim 20: 1$ (corresponding to $2.5 \mathrm{mM}$ ATP and $135 \mu \mathrm{M}$ protein), but measurements at higher ratios were prevented by ATP's high absorbance. For the ATP/ Cox13 ratios possible to assay in $\mathrm{CD}$ experiments, slight changes in secondary structure were observed (Additional file 1: Figure S9B). The changes indicate a small increase in helicity, as the absolute intensities of the peaks at 208 and $222 \mathrm{~nm}$ increased.

Next, the influence of ATP on ${ }^{15} \mathrm{~N}$-labeled Cox13 was assayed by monitoring chemical shift changes in ${ }^{1} \mathrm{H}_{-}{ }^{15} \mathrm{~N}-\mathrm{HSQC}$ spectra. Spectra were collected at six different concentrations of ATP (with the same protein concentration as in the $\mathrm{CD}$ experiments) resulting in ligand/protein ratios of 2:1, 5:1, 10:1, 25:1, 50:1, and 100:1 (Fig. 5a and Additional file 1: Figure S8), the highest ratio corresponding to $[\mathrm{ATP}]=13 \mathrm{mM}$. Higher ATP/Cox13 concentration ratios induced protein aggregation, possibly due to larger conformational changes in Cox13 induced by ATP. From the incremental addition of ATP to Cox13 in the NMR titrations, we observed gradual shift changes in resonance positions. A chemical shift perturbation (CSP) analysis across the sequence (Fig. 5a) revealed that the most affected residues are located in two distinct regions of the Cox13 structure; in the loop region immediately following the TM-helix (R81, H83, K85), and in the beginning of $\alpha 3$ (R94, Y96). A residue at the $\mathrm{C}$ terminus was also significantly affected by ATP addition (I125). Examples of CSPs as a function of the ligand/protein ratio are shown in Fig. $5 b$ for four of the most affected residues. The higher CSPs suggest that these residues are in direct contact with ATP or are indirectly affected by the environmental changes produced by ATP binding, e.g., through conformational rearrangement of the protein. We note that although full saturation has not been achieved, the data indicates that at the highest concentration we see an onset of saturation for all residues. A global $K_{\mathrm{d}}$ of $15 \pm 2 \mathrm{mM}$ was readily fitted to the data for all residues that displayed large CSPs, indicating that the changes in chemical shifts are consistent with one single binding event (Fig. 5).

To investigate the corresponding effects, those on ATP upon binding of the Cox13 protein, changes in ${ }^{31} \mathrm{P}$ NMR spectra of ATP were monitored in a titration series of ATP to unlabeled Cox13. Significant ${ }^{31} \mathrm{P}$ chemical shift changes were observed for the terminal, negatively charged phosphate group of ATP, with only minor changes for the central phosphate and no effect on the innermost one, indicating that electrostatic interactions are important for binding (Fig. 5c and Figure S9).

We also titrated ADP to Cox13 in the same way as for ATP, and the results are shown in Additional file 1: Figure S10. Overall, chemical shift changes suggest that ADP interacts with Cox13 in a similar manner as ATP, with the same residues being affected by the nucleotide. Also the fitted $K_{\mathrm{d}}$ values were very similar $(17 \pm 2 \mathrm{mM}$ for ADP vs $15 \pm 2 \mathrm{mM}$ for ATP). Similarly as for ATP, the terminal phosphate in ADP was the most affected part of the molecule upon addition of Cox13. However, Cox13 was not observed to precipitate together with ADP at the final titration step, possibly indicating a difference in the interaction between Cox13 and the two nucleotides at higher ligand concentrations.

In order to model how Cox13 interacts with ATP in our studies, the CSP data were used to direct docking of ATP to the Cox13 NMR structure. Due to the NMR ensemble's large conformational heterogeneity, good binding scores were obtained in several Cox13 C-terminal structural arrangements (Fig. 6). The top-scoring models had extensive electrostatic contacts in common, between the negatively charged phosphate groups of ATP and the positively charged side-chains or polar backbone amide groups of residues in the loop preceding the $\alpha 3$ helix, e.g., R81, H83, and K85. The cluster with the best HADDOCK score $(-91 \pm 4)$ had well-defined electrostatic $\left(-290 \pm 40 \mathrm{kcal} \mathrm{mol}^{-1}\right)$ and Van der Waals $(-22 \pm 4 \mathrm{kcal}$ $\mathrm{mol}^{-1}$ ) energies. Three top-scoring models from this cluster are displayed in Fig. 6a. Although the top-scoring models never made simultaneous, direct contact with ATP using all residues with large CSPs, good overall docking scores could be obtained where different combinations of perturbed residues participated. This indicates either that the interaction can occur in several ways or that some residues with large CSPs are indirectly affected by ATP binding. Furthermore, it is possible that Cox13 forms other contacts with ATP in addition to those residues identified by NMR and ${ }^{1} \mathrm{H}_{-}{ }^{15} \mathrm{~N}-\mathrm{HSQC}$ analysis. Our data is therefore most consistent with the presence of several possible Cox13-ATP complexes (for 


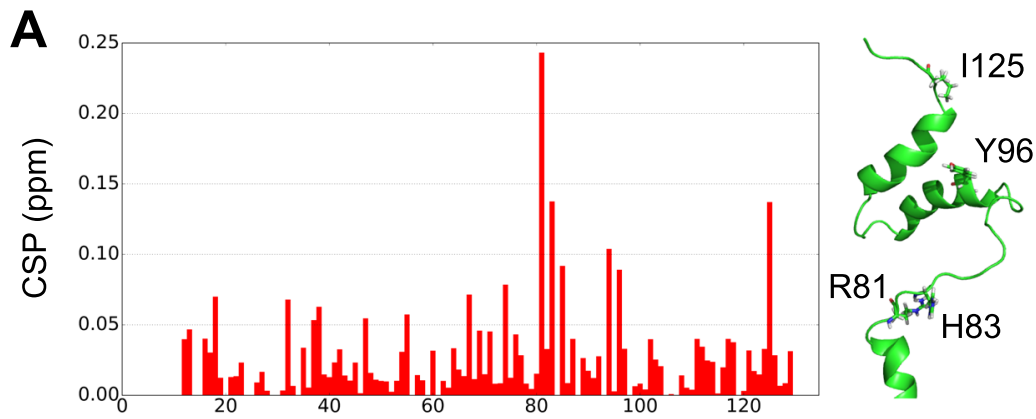

B

Residue Number

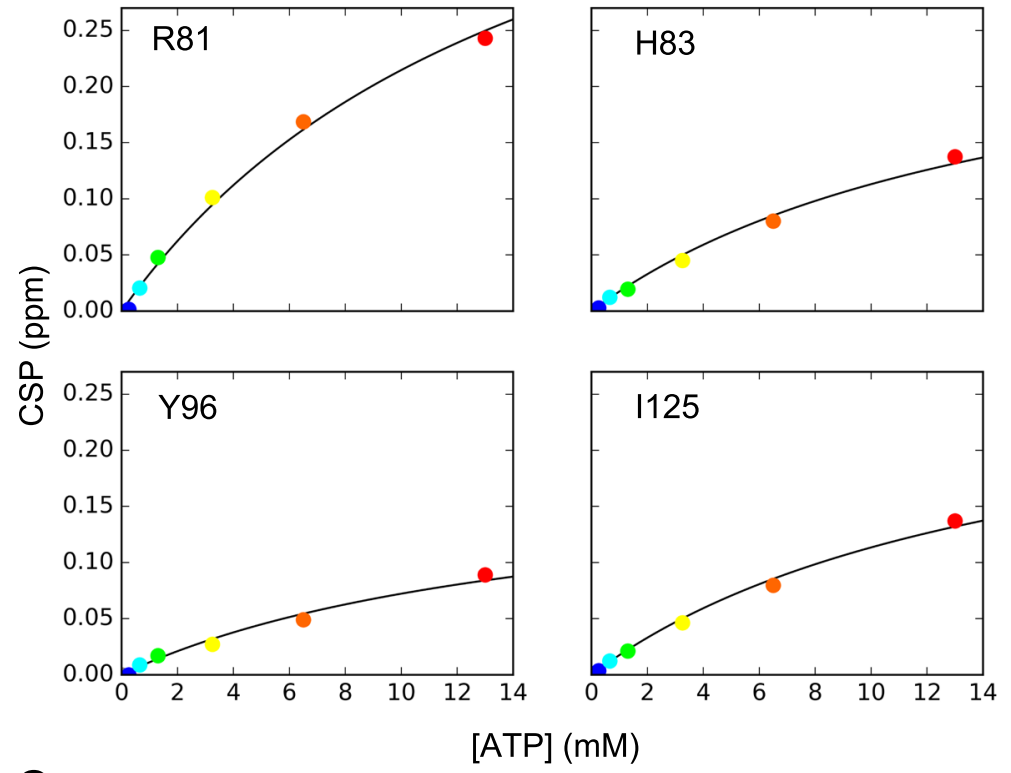

C

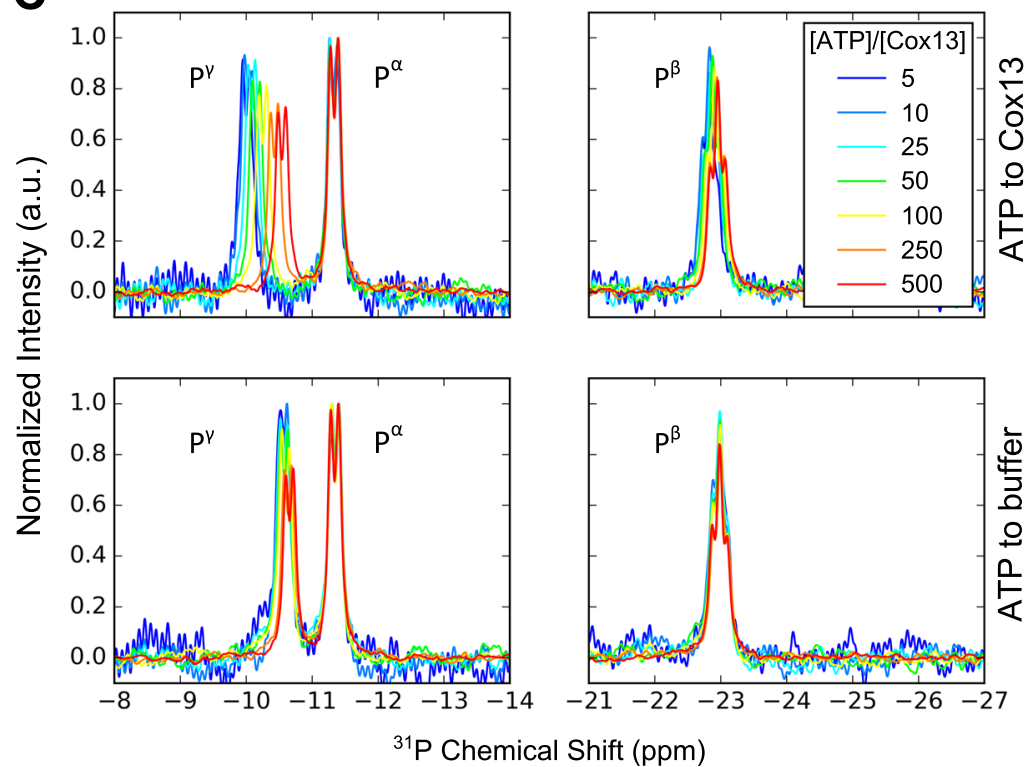

Fig. 5 (See legend on next page.) 
(See figure on previous page.)

Fig. 5 Interaction of Cox13 with ATP. a CSPs of Cox13 upon ATP addition, for ${ }^{15} \mathrm{~N}-\mathrm{HSQC}$ spectra, see Additional file 1: Figure S8. CSPs as a function of primary sequence calculated from peak positions in ${ }^{15} \mathrm{~N}-\mathrm{HSQCS}$ at the initial and final titration steps of [ATP]/[Cox13] $=0$ and 100, respectively (left). The residues with the largest CSPs are indicated as sticks on a representative structure from the NMR ensemble (right). $\mathbf{b}$ CSP as a function of ATP/Cox13-concentration ratio for the residues highlighted in $\mathbf{a}$. The curves are in the form of Eq. 6 in [39] with globally fitted $K_{d}=$ $15 \pm 2 \mathrm{mM}$. The fitted maximum CSPs for residues R81, H83, Y96, and 1125 are $0.55 \pm 0.04,0.29 \pm 0.02,0.18 \pm 0.02$, and $0.29 \pm 0.02$ ppm, respectively. c Part of ${ }^{31} \mathrm{P}$ spectra showing signals from the three phosphate groups of ATP in solutions with (upper panels) and without Cox 13 (lower panels) at the concentration ratios given in the legend. The lower panels were obtained on a sample where ATP stock solution was added in the corresponding amounts to NMR buffer only. To ease shift change comparisons between signals from spectra with large ATP concentration differences, spectra have been normalized to the same $P^{a}$ peak intensity

the isolated Cox13 subunit), but that the interactions are confined to the C-terminal region of Cox13, including a few charged residues.

\section{Discussion}

It is clear from our data that the interaction between ATP and Cox13 occurs in the C-terminal region of Cox13, located in the intermembrane space. The bovine CoxVIa residues at the $\mathrm{N}$ terminus (matrix) suggested to be involved in ATP binding (Arg14 and Arg17) are not conserved in yeast Cox13, which could explain this difference [2]. However, the $\mathrm{C}$ terminus is highly conserved; specifically, the R81 and Y96 residues identified here to be in interaction with ATP are conserved in various species (Fig. 1d), suggesting that the binding of ATP to the Cox13 protein family may be a common feature. The conserved GDGXX [T/S] (where the first $G$ is $\mathrm{G} 109$ and $\mathrm{X}$ is any amino acid) motif suggested by Taanman to be involved in the binding of ATP by Cox-13 [20] is in the same conserved region of the Cox13 protein (Fig. 1d) which also bears some similarity to the KXR/SXN ATP-binding motif in threonylcarbamoyl-AMP synthase [40, 41].

What could be the functional effect of binding ATP to Cox13 in the context of the entire $\mathrm{CytcO}$ complex? Based on the structural location (Fig. 6b) of Cox13 and our data showing effects on the low $K_{\mathrm{m}}$ for cyt. $c$ in Cox13 $\Delta-\mathrm{Cyt} c \mathrm{O}$, we suggest that the Cox13 subunit is involved in forming the surface for electron donation, consistent with previous data suggesting that cyt. $c$ docks in the vicinity of Cox13 $[9,42,43]$ in the cleft lined by Cox1, Cox2, Cox3, and Cox12 (Fig. 6b). This binding site would then "open up" to yield a higher affinity for cyt. $c$ in the absence of Cox13.

In the presence of $5 \mathrm{mM}$ ATP, there are two effects on the interaction between cyt. $c$ and $\mathrm{Cyt} c \mathrm{O}$ (Figs. 4 and S7); the overall affinity is lowered, but the maximum activity is increased. Both these effects are seen also in the Cox13 $\Delta-$-CytcO, but the overall rate increase is higher in the absence of Cox13. The effect of ATP on CytcO is thus consistent with a complex behavior with more than one interaction site with different effects, as previously suggested [20]. If we assume that there are two ATP binding sites on $\mathrm{Cyt} c \mathrm{O}$, one at an undefined location that leads to a lower affinity for cyt. $c$ but a higher maximum activity, then our data is consistent with a second binding site for ATP with an inhibitory role on Cox13, since the overall rate stimulation by ATP is higher in its absence. Thus, ATP binding to Cox13 would be involved in regulating the mode (but not the affinity) of cyt. $c$ binding to $\mathrm{Cyt} c \mathrm{O}$ and thereby decrease the overall maximum rate of electron transfer from cyt. $c$ into the electron acceptor $\mathrm{Cu}_{\mathrm{A}}$.

The fitted $K_{\mathrm{d}}$ of $15 \mathrm{mM}$ for the ATP binding to Cox13 observed in NMR titrations (Fig. 5) occurs in the same region as the tentative $K_{\mathrm{d}}$ fitted for ATP effects on
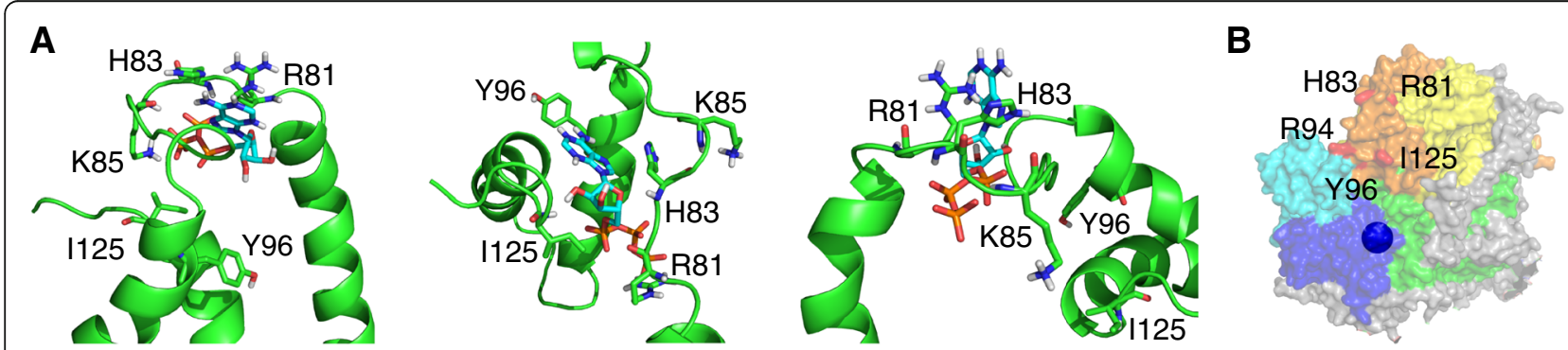

Fig. 6 Cox13-ATP interaction models and location of the ATP binding site in the full yeast CytcO. a The three top-scoring Cox13-ATP interaction models from Haddock. Cartoon representation of the $\mathrm{C}$ terminus of Cox13, with ATP and residues discussed in the text displayed as sticks. $\mathbf{b}$ The location of identified ATP-binding residues (residues numbered and displayed in red) on the $\mathrm{II}_{2} \mathrm{IV}_{2}$ cryo-EM structure surface [7]. Only Complex IV (one monomer) is shown with Cox13 in orange, Cox2 and $\mathrm{Cu}_{\mathrm{A}}$ (which sits below the surface) in blue, Cox 1 in green, Cox3 in yellow, and Cox 12 in cyan. The images were prepared in Pymol 
turnover of $\mathrm{Cyt} c \mathrm{O}$ (Additional file 1: Figure S7), and we also see clear effects on cyt. $c$ titrations at $5 \mathrm{mM} \mathrm{ATP}$ (Fig. 4). The higher values obtained in NMR titrations could be due to the presence of added Arg and Glu in the NMR buffer (to stabilize the protein for the long NMR experiments), which presumably shields electrostatic interactions. We note that these ATP binding effects on Cox13 (and $\mathrm{CytcO}$ ) occur in the $\mathrm{mM}$ region, which is consistent with the concentrations measured for cytosolic ATP in mammalian and yeast mitochondria $(5 \mathrm{mM})$ and the ADP concentration is typically $5-10$ times lower $([44,45]$, with the lower range of ATP/ADP ratios observed in yeast). This means that even if ADP binds with similar $K_{\mathrm{d}}$ (Additional file 1: Figure S8), the much lower concentrations of ADP would favor ATP binding.

\section{Conclusion}

In summary, our study provides structural information for an important subunit of $\mathrm{Cyt} c \mathrm{O}$ that was used for identifying residues that are affected by the binding of ATP. Our data suggest that Cox13 houses an allosteric binding site for ATP in the intermembrane space and provides additional and significant insight into the $\mathrm{Cyt} c \mathrm{O}$ enzymatic process and regulation.

\section{Methods}

\section{Protein expression and purification}

The gene of Cox13 from S. cerevisiae was cloned into pET-28a (Novagen) and expressed in E. coli Rosetta 2 as a His-tagged fusion (at $\mathrm{C}$ terminus) protein. The procedure used was similar to the one used to purify Rcf1 and Rcf2 $[46,47]$ with some minor differences in buffer composition. Cells were grown at $37^{\circ} \mathrm{C}$ to an $\mathrm{A}_{600}$ of 0.5 , induced with $1 \mathrm{mM}$ IPTG, and allowed to express the protein for $12 \mathrm{~h}$ before harvesting. The media used was M9 minimal medium containing ${ }^{15} \mathrm{~N}$ ammonium chloride and/or ${ }^{13} \mathrm{C}$ glucose (Cambridge Isotopes Laboratory). The bacterial pellet was re-suspended and passed through a French press, and the Cox13 inclusion bodies were purified under denaturing conditions $(20 \mathrm{mM}$ Tris, pH 8.0, $300 \mathrm{mM} \mathrm{NaCl}, 5 \mathrm{mM}$ 2-mercaptoethanol, $5 \mathrm{mM}$ imidazole, and $6 \mathrm{M}$ guanidinium chloride) by affinity chromatography on Ni-NTA resin (Sigma). The purified denatured inclusion bodies were dialyzed against water to precipitate the inclusion bodies, which were then resolubilized with $2 \mathrm{~mL} 8 \mathrm{M}$ guanidinium chloride. The 2 $\mathrm{mL}$ re-solubilized inclusion bodies were slowly diluted into $20 \mathrm{~mL}$ refolding buffer $\left(20 \mathrm{mM} \mathrm{NaP}_{\mathrm{i}} \mathrm{pH} 6.5,300\right.$ $\mathrm{mM} \mathrm{NaCl}, 500 \mathrm{mM}$ arginine, $0.5 \mathrm{mM}$ oxidized glutathione, $5 \mathrm{mM}$ reduced glutathione, $10 \%$ glycerol, $1 \mathrm{mM}$ EDTA, and $3 \mathrm{mM}$ DPC) with stirring at $4{ }^{\circ} \mathrm{C}$ overnight. Next, the refolded Cox 13 protein was concentrated and loaded onto a Superdex 200 10/300 column (GE
Healthcare) pre-equilibrated with gel filtration buffer (20 $\mathrm{mM} \mathrm{NaP}_{\mathrm{i}} \mathrm{pH}$ 6.5, $50 \mathrm{mM}$ L-Arg, $50 \mathrm{mM}$ L-Glu [48], 1 $\mathrm{mM}$ DTT, $3 \mathrm{mM}$ DPC, or DPC- $\mathrm{d}_{38}$ ). The fractions containing Cox13 protein were concentrated, and the concentration was determined by a Lowry assay.

\section{Circular dichroism spectroscopy}

For CD experiments, a Cox13 NMR sample was exchanged into a CD compatible buffer using a PD10 column (GE Healthcare), followed by concentration using a centrifugal concentrator with $10 \mathrm{kDa}$ molecular weight cut-off. The CD buffer consisted of $30 \mathrm{mM}$ DPC, 25 $\mathrm{mM} \mathrm{KP}$ i pH 6.5, $1 \mathrm{mM}$ DTT, and $50 \mathrm{mM} \mathrm{K}_{2} \mathrm{SO}_{4}$ to replace free Arg and Glu in the NMR buffer. The final CD samples consisted of 7.6 or $135 \mu \mathrm{M}$ Cox13, as determined from the $A_{280}$, for measurements of a single $C D$ spectrum and for the ATP titration series, respectively. Quartz cuvettes with path lengths of $1 \mathrm{~mm}$ and $50 \mu \mathrm{m}$ where used in the former and latter experiments, respectively.

CD spectra were recorded on a Chirascan spectrometer (Applied Photophysics). The temperature was set to $298 \mathrm{~K}$ using an external water bath. Spectra were obtained in $1 \mathrm{~nm}$ steps from 260 to $190 \mathrm{~nm}$ with a measurement time of $0.5 \mathrm{~s}$ at each wavelength. Ten scans were acquired and averaged. For the ATP titration experiments, the final ATP concentrations were 0,1 , or 2.5 $\mathrm{mM}$ in CD buffer. The collection of high-quality spectra at even higher concentration ratios was prohibited by the strong absorption of ATP in the lower wavelength part of the spectrum. For each titration step, a background spectrum was recorded by adding the corresponding amount of ATP to the CD buffer only. Background spectra were subtracted from the ones with protein, and spectra were corrected for dilution upon ATP addition and normalized to units of mean residue molar ellipticity. Finally, CD spectra were smoothened through averaging within a three-point window function.

\section{NMR spectroscopy}

All NMR data were obtained at $40{ }^{\circ} \mathrm{C}$ on Bruker 900 $\mathrm{MHz}$ or $800 \mathrm{MHz}$ spectrometers equipped with cryogenic probes. Spectra were processed with the software TopSpin (Bruker) and analyzed using CcpNmr [49]. The concentration of ${ }^{15} \mathrm{~N},{ }^{13} \mathrm{C}$-labeled Cox13 was $0.5 \mathrm{mM}$ in $20 \mathrm{mM} \mathrm{NaP}$ pH 6.5, $50 \mathrm{mM} \mathrm{L-Arg,} 50 \mathrm{mM} \mathrm{L}-\mathrm{Glu}, 1$

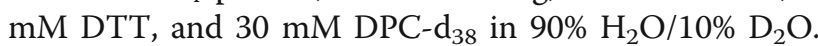
Backbone chemical shifts were assigned in a sequential manner from the following experiments: $2 \mathrm{D}{ }^{1} \mathrm{H}-{ }^{15} \mathrm{~N}$ TROSY-HSQC and 3D TROSY-versions of the HNCA, $\mathrm{HN}(\mathrm{CO}) \mathrm{CA}, \mathrm{HNCO}, \mathrm{HN}(\mathrm{CA}) \mathrm{CO}, \mathrm{HNCACB}$, and $\mathrm{HN}(\mathrm{CO}) \mathrm{CACB}$ spectra [50-52]. Sidechain proton and carbon chemical shifts were assigned using the following experiments: 3D $(\mathrm{H}) \mathrm{CCH}-\mathrm{TOCSY}, 3 \mathrm{D} \mathrm{CC}(\mathrm{CO}) \mathrm{NH}$, and 
3D $\mathrm{H}(\mathrm{CCO}) \mathrm{NH}$ spectra [53, 54]. NOEs were obtained from $3 \mathrm{D}{ }^{15} \mathrm{~N}-\mathrm{NOESY}-\mathrm{HSQC}$ (mixing time $(\mathrm{TNOE})=$ $100 \mathrm{~ms}), 3 \mathrm{D}{ }^{13} \mathrm{C}-\mathrm{NOESY}-\mathrm{HSQC}(\mathrm{\tau NOE}=100 \mathrm{~ms})$ and 3D SOFAST $-{ }^{13} \mathrm{C}-\mathrm{HMQC}-\mathrm{NOESY}-{ }^{13} \mathrm{C}-\mathrm{HMQC}$ ( $\mathrm{TNOE}=$ $100 \mathrm{~ms})$ spectra $[55,56]$. The $3 \mathrm{D} \mathrm{F} 1-{ }^{13} \mathrm{C} /{ }^{15} \mathrm{~N}$-filtered, F3- ${ }^{15} \mathrm{~N}$-edited-NOESY-HSQC $(\mathrm{TNOE}=200 \mathrm{~ms})$ and 3D F1- ${ }^{13} \mathrm{C} /{ }^{15} \mathrm{~N}$-filtered, $\quad \mathrm{F} 3-{ }^{13} \mathrm{C}$-edited-NOESY-HSQC $(\mathrm{\tau NOE}=200 \mathrm{~ms})$ spectra were acquired using a sample that was reconstituted with a $1: 1$ mixture of ${ }^{15} \mathrm{~N}-,{ }^{13} \mathrm{C}$ labeled Cox13 and unlabeled Cox13 to assign the intermolecular NOE contacts [25]. The mixing of the labeled and unlabeled sample was performed at the level of inclusion bodies.

${ }^{31} \mathrm{P}$ experiments were performed on a Bruker 400 $\mathrm{MHz}$ spectrometer equipped with a $\mathrm{BBO}$ probe. The temperature was set to $298 \mathrm{~K}$.

\section{Structure calculation}

The ARIA program (version 2.3) [57] was used to help the assignment of short- and middle-range cross-peaks automatically. The program CNS (version 1.21) [26] was used to generate the structures through a simulated annealing protocol. The torsion angle restraints were determined from backbone chemical shift data using DANGLE [58]. The manually and automatically assigned unambiguous short-range and medium-range, as well as the manually assigned unambiguous long-range distance restraints were used for the monomer structure calculation. Monomer structures were calculated by 180 ps of torsion angle dynamics, followed by 72 ps of slow cooling in torsion angle space and 72 ps of slow cooling in cartesian space. In the next round of dimer structure calculation, two copies of the lowest-energy monomer structure were used to construct the dimer model by combining the unambiguous inter-monomer distance restraints derived from 3D F1 $-{ }^{13} \mathrm{C} /{ }^{15} \mathrm{~N}$-filtered, F3- ${ }^{15} \mathrm{~N}$-edited-NOESY-HSQC and 3D F1- ${ }^{13} \mathrm{C} /{ }^{15} \mathrm{~N}$-filtered, F3- ${ }^{13} \mathrm{C}$-edited-NOESY-HSQC spectra. A total of 100 structures were calculated and the 15 lowestenergy structures were selected to represent the structural ensemble. Protein structures were analyzed using PROCHECK [59] and displayed using Chimera [60]. Structural statistics are summarized in Additional file 1: Table S1.

\section{Paramagnetic spin-label titration}

Water-soluble gadodiamide (Omniscan) was added from a $0.5 \mathrm{M}$ stock solution into $500 \mu \mathrm{l}{ }^{15} \mathrm{~N}$-labeled Cox13 with the final concentrations of $1 \mathrm{mM}, 5 \mathrm{mM}$, and 10 $\mathrm{mM}$. The detergent-soluble 16-DSA powder was dissolved in methanol, divided into aliquots corresponding to final concentrations of $1 \mathrm{mM}, 5 \mathrm{mM}$, and $10 \mathrm{mM}$ in the Cox13 sample, and methanol was air-dried away before adding to the protein. 2D ${ }^{1} \mathrm{H}_{-}{ }^{15} \mathrm{~N}$-TROSY-HSQC spectra were recorded at $40{ }^{\circ} \mathrm{C}$ for each concentration of spin-label reagent, together with spectra before addition of spin-label to obtain reference resonance intensities. As a qualitative measure of a residue's distance to a paramagnetic species, intensity ratios $I / I_{\text {ref }}$ were calculated where $I$ and $I_{\text {ref }}$ are peak intensities in spectra with and without spin-label, respectively. Resonances that could not be assigned unambiguously by comparison to assigned reference spectra were excluded from the analysis, as well as resonances with large overlap, or large intensity increases after spin-label addition (i.e., due to decreasing exchange dynamics). Relative uncertainties in intensity ratios were calculated by assigning an arbitrary error to all peaks (5\% of average reference spectrum peak intensity) followed by error propagation. To aid identification of trends in intensity ratios as a function of sequence, a weighted moving average was calculated, weighting by sequential distance (according to a Gaussian distribution with three residue halfwidth) and relative uncertainties in intensity ratios.

\section{Yeast strain construction and purification of CytcO}

Two strain variants were used to purify $\mathrm{Cyt} c \mathrm{O}$, a W303 strain with a 6xHis-tag on Cox13 [61] and a BY4741 Cox13 $\Delta$ strain with a Flag-tag on Cox6. The strain BY4741 cox $13 \Delta$ Cox6Flag was constructed by first introducing a Flag-tag by exchanging the endogenous stop codon of the COX6 open reading frame with a Flag-tag followed by a HIS3 selection cassette. Subsequently, COX13 was deleted by homologous recombination with a KanMX4 selection cassette.

Yeast cells were grown on YP-media (2\% peptone and $1 \%$ yeast extract, $\mathrm{pH}$ of the media adjusted to 5.5 ) supplemented with $2 \%$ glycerol.

Membranes from crushed yeast cells were used as starting material for the protein purification. Membranes were prepared by harvesting the yeast cells $(5500 \times g$ for 5 min) followed by a wash in $50 \mathrm{mM} \mathrm{KP_{i }}$ buffer $\mathrm{pH}$ 7.4. The cell pellet was suspended in buffer $(0.4 \mathrm{M}$ sorbitol, $50 \mathrm{mM} \mathrm{KP}$ buffer $\mathrm{pH} 7.4$, and $5 \mathrm{mM}$ EDTA) at the ratio of $1: 3(\mathrm{w} / \mathrm{v})$ and run twice through a cell disruptor (Constant Systems LTD) at 35000 psi. A few crystals of phenylmethanesulfonyl fluoride (PMSF) were added immediately after the crushing step. The cell homogenate was centrifuged at $5500 \times g$ for $10 \mathrm{~min}$ to remove unbroken cells. The supernatant was centrifuged at $138,000 \times g$ for $1 \mathrm{~h}$ to pellet membranes. The membranes were washed once in buffer

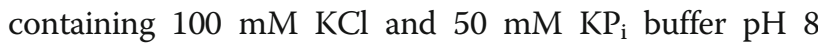

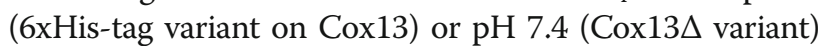
and then homogenized in wash buffer to a protein concentration $\sim 20 \mathrm{mg} / \mathrm{ml}$ and flash-frozen in liquid nitrogen until further use.

His-tagged $\mathrm{CytcO}$ was purified according to a procedure by Meunier et al. [61] with the following modifications: during solubilization, the membranes were diluted to $2 \mathrm{mg}$ protein $/ \mathrm{ml}$, dodecyl- $\beta$-D-maltoside (DDM) 
concentration was $1.5 \%(\mathrm{w} / \mathrm{v})$ and the buffer contained an additional $100 \mathrm{mM} \mathrm{KCl}$. Solubilization lasted $1 \mathrm{~h}$ at 5 ${ }^{\circ} \mathrm{C}$ with mild stirring. After solubilization, the solution was run through a Bio-Rex 70 cation exchanger (BIORAD) to remove cytochrome $c$ from the membranes. The resin was converted to the potassium form. Five grams of cation exchanger $/ 100 \mathrm{ml}$ of solution was used. After cation exchange, the solubilized membranes were loaded at $\sim 0.2 \mathrm{ml} / \mathrm{min}$ on a $\mathrm{Ni}$ sepharose 6 fast flow matrix (GE Healthcare) equilibrated with $20 \mathrm{mM} \mathrm{KP_{ \textrm {i } }}$ buffer $\mathrm{pH} 8,150 \mathrm{mM} \mathrm{KCl}$ and $0.035 \%$ DDM. The column was washed with 5 column volumes of the same buffer containing $10 \mathrm{mM}$ imidazole. Elution was performed with 4 column volumes of buffer with $40 \mathrm{mM}$ imidazole followed by 4 column volumes containing 100 $\mathrm{mM}$ imidazole. The DEAE sepharose column step was omitted, and the eluted fractions were concentrated and pooled. During concentration, buffer exchange was performed to reduce the imidazole concentration to the $\mu \mathrm{M}$ range.

Flag-tagged cytochrome $c$ oxidase was purified with the following method: solubilization was performed in the same way as for the His-tagged CytcO with the exception that the $\mathrm{pH}$ of the buffer was 7.4. After solubilization, the solution was diluted in buffer (100 $\mathrm{mM} \mathrm{KCl}, 50 \mathrm{mM} \mathrm{KP}$ buffer $\mathrm{pH}$ 7.4) to a DDM concentration of $0.2 \%$. If the volume exceeded $100 \mathrm{ml}$, the solution was concentrated below that volume. The solution was loaded on $2 \mathrm{ml}$ of anti-FLAG M2 affinity gel equilibrated with buffer $(150 \mathrm{mM} \mathrm{KCl}, 20 \mathrm{mM} \mathrm{KP}$ buffer $\mathrm{pH}$ 7.4 , and $0.035 \% \mathrm{DDM})$. The column was then washed with 20 column volumes of the equilibration buffer followed by elution with 5 column volumes of the same buffer with the addition of $0.1 \mathrm{mg} / \mathrm{ml} 1 \times$ Flag peptide. The eluted oxidase was concentrated with a $100 \mathrm{kDa}$ cutoff filter (Merck Millipore) and frozen in liquid nitrogen.

\section{Cytochrome $c$ oxidase activity measurements in the presence and absence of nucleotides}

$\mathrm{Cyt} c \mathrm{O}$ activity was measured by monitoring the oxygen consumption of purified yeast enzyme from wildtype and $\Delta$ Cox13-variant as a function of added yeast cyt. $c$ both in the absence and presence of $5 \mathrm{mM}$ ATP. The activity was also measured in the presence and absence of ATP and ADP at varying concentrations. The measurements were performed with a Clark-type electrode (Hansatech Instruments). The buffer was composed of 25 $\mathrm{mM} \mathrm{KP_{i }}$ pH 6.2 or $100 \mathrm{mM} \mathrm{KP_{i }}$ pH 7.0 and $0.035 \%$ $\mathrm{DDM}$, and the measurement volume was $1 \mathrm{ml}$ after the final addition. Ascorbate $(10 \mathrm{mM})$, TMPD $(0.1 \mathrm{mM})$, and cyt. $c$ from yeast $(50 \mu \mathrm{M}$, or for the titrations at the concentrations indicated) were used as electron donors. The nucleotide stock solutions were dissolved in equimolar amounts of $\mathrm{KP}_{\mathrm{i}}$ buffer at $\mathrm{pH} 6.2$ or $\mathrm{pH}$ 7.0. The background rate after addition of the reductants was subtracted from the final rates.

\section{ATP titration}

The ${ }^{15} \mathrm{~N}$-labeled Cox13 sample was $0.5 \mathrm{mM}$ in a buffer of $20 \mathrm{mM} \mathrm{NaP}$, pH 6.5, $50 \mathrm{mM}$ L-Arg, $50 \mathrm{mM} \mathrm{L-Glu,} 1$ $\mathrm{mM}$ DTT, and $30 \mathrm{mM}$ DPC in $90 \% \mathrm{H}_{2} \mathrm{O} / 10 \% \mathrm{D}_{2} \mathrm{O}$. 0.5 $\mathrm{M}$ stock solution of ATP (Sigma) in the same buffer as Cox13 was titrated into the Cox13 sample that provided the following molar ratios of ligand to protein: $2: 1,5: 1$, 10:1, 25:1, 50:1, and 100:1. A 2D ${ }^{1} \mathrm{H}_{-}{ }^{15} \mathrm{~N}-\mathrm{HSQC}$ spectrum was collected at each titration point. The weighted total shift change, the chemical shift perturbation (CSP), for each peak was calculated by CSP $=\sqrt{(\Delta \delta H)^{2}+(\alpha \Delta \delta N)^{2}}$, where $\Delta \delta \mathrm{H}$ and $\Delta \delta \mathrm{N}$ are the chemical shift differences for ${ }^{1} \mathrm{H}$ and ${ }^{15} \mathrm{~N}$, respectively, and $\alpha$ a shift weighting factor of 0.2 for Gly and 0.14 for other residues [39].

${ }^{31} \mathrm{P}$ NMR was used to monitor the effect of Cox13 on ATP. The sample consisted of $600 \mu \mathrm{L} 22 \mu \mathrm{M}$ unlabeled Cox13 in NMR-buffer $(25 \mathrm{mM} \mathrm{KP}$ pH 6.5, $50 \mathrm{mM}$ Arg, $50 \mathrm{mM}$ Glu, $1 \mathrm{mM}$ DTT, $10 \% \mathrm{D}_{2} \mathrm{O}$ ) with $45 \mathrm{mM}$ DPC. A $100-\mathrm{mM}$ ATP stock solution in $100 \mathrm{mM} \mathrm{NaP}$ i $\mathrm{pH} 6.5$ was used for the titrations. $1 \mathrm{D}{ }^{31} \mathrm{P}$ spectra were recorded for $[\mathrm{ATP}] /[$ Cox13]-ratios of $1,5,10,25,50,100,250$, and 500. For each ATP titration step to Cox13, a background spectrum was recorded on the corresponding ATP concentration in NMR buffer with $30 \mathrm{mM}$ DPC but without protein. Due to the large range of ATP concentrations, experimental time varied between several hours down to a couple of minutes per spectrum to achieve approximately the same level of signal to noise in all spectra. The recycle delay was set to $1 \mathrm{~s}$.

\section{HADDOCK docking procedure}

ATP was docked to Cox13 using HADDOCK [62], and the interaction was guided based on the results of the NMR chemical shift perturbation experiments. Residues R81, H83, Y96, and I125, which displayed large CSPs were considered active in binding, and their amide protons were unambiguously constrained to a distance of $2.5 \pm 2.5 \AA$ from a central atom of the ATP molecule $\left(\mathrm{C}^{\prime}\right)$. The docking was performed simultaneously to all subunits $A$ of the NMR ensemble and subsequently to all subunits B. To allow for a broad search of Cox13's conformational space, the region between $\alpha 2$ and $\alpha 3$, and the C-terminal loop were considered fully flexible. 10,000 structures were initially generated, out of which 1000 and 500 were refined and water-refined, respectively. Apart from the aforementioned settings, default parameters were used throughout all docking procedures. 


\section{Abbreviations}

CytcO: Cytochrome c oxidase; cyt.: Cytochrome; DDM: N-dodecyl- $\beta$-Dmaltoside; TMPD: N,N,N',N'-tetramethyl-p-phenylenediamine; $\mathrm{P}_{\mathrm{i}}$ : Inorganic phosphate $\left(\mathrm{HPO}_{4}{ }^{2-}\right.$ and $\left.\mathrm{H}_{2} \mathrm{PO}_{4}{ }^{-}\right)$; $\mathrm{CSP}$ : Chemical shift perturbation; TM: Transmembrane

\section{Supplementary Information}

The online version contains supplementary material available at https://doi. org/10.1186/s12915-021-01036-x.

\begin{abstract}
Additional file 1: Figure S1. Purification and characterization of Cox13 in micelles. Figure S2. Representative sequential backbone assignment of Cox13. Figure S3. Representative slices in the $3 \mathrm{D}{ }^{15} \mathrm{~N},{ }^{13} \mathrm{C}$-edited NOESY spectra. Figure S4. Representative slices from the $3 \mathrm{D}{ }^{15} \mathrm{~N}$-edited/ filtered NOESY spectra. Figure S5. Paramagnetic spin-label titrations. Figure S6. Catalytic turnover of wildtype and Cox13 $\mathrm{CytcO}$. Figure S7. Turnover in wildtype and $\mathrm{Cox} 13 \Delta \mathrm{CytcO}$ as a function of added yeast cytochrome $c$. Figure S8. Interaction of Cox13 with ATP. Figure S9. Interaction of ATP with Cox13. Figure S10. Interaction of Cox13 with ADP. Table S1. Summary of structural ensemble statistics. Table S2. Intermolecular NOEs.

Additional file 2. Excel file with data related to Fig. 4.

Additional file 3. Original picture related to Additional file 1: Figure S1.

Additional file 4. Excel file with data for Additional file 1: Figure S5.

Additional file 5. Excel file with data for Additional file 1: Figure S6.

Additional file 6. Excel file with data for Additional file 1: Figure S10.
\end{abstract}

\section{Acknowledgements}

The Swedish NMR Centre, Gothenburg, and Dr. Cecilia Persson, and the NMR Facility at the University of Frankfurt, are acknowledged for access to NMR spectrometers and for technical assistance. We thank Martin Ott (Stockholm University) for discussions and advice on the construction of the yeast strains.

\section{Authors' contributions}

S.Z, P. Ä, and L. M designed the study, S. Z and M. B prepared the Cox13 samples for all experiments, M. B prepared and analyzed the CytcO samples, and $\mathrm{H}$. D constructed the yeast strains; P. P and S. Z collected the NMR data; S. Z, P.P, and L. M analyzed the NMR data; M. B, P.Ä and P. B analyzed the CytcO activity data; S. Z, L. M, P. P, and P. Ä wrote the manuscript with parts contributed by M. B, and all authors contributed to the discussions and editing of the manuscript. The authors read and approved the final manuscript.

\section{Funding}

This study was supported by a grant from the Knut and Alice Wallenberg Foundation to PB and PÄ (grant number 2013.0006) and by a grant from the Swedish Research Council (VR grant number 2018-03395) to LM. The NMR work done at the University of Frankfurt was supported by iNEXT, grant number 653706, funded by the Horizon 2020 program of the European Commission. Open access funding provided by Stockholm University.

\section{Availability of data and materials}

All data generated or analyzed during this study are included in this published article, its supplementary information files, and publicly available repositories. Accession codes: The structural restraints and structure coordinates have been deposited with accession codes 6ZDB (to PDB) and 34522 (to BMRB), respectively.

\section{Declarations}

\section{Ethics approval and consent to participate}

Not applicable.

\section{Consent for publication}

Not applicable.

\section{Competing interests}

The authors declare that they have no competing interests.

\section{Author details}

${ }^{1}$ Department of Biochemistry and Biophysics, Stockholm University, Stockholm, Sweden. ${ }^{2}$ Current address: High Magnetic Field Laboratory, Hefei Institutes of Physical Science, Chinese Academy of Sciences, Hefei, China.

Received: 16 July 2020 Accepted: 22 April 2021

Published online: 10 May 2021

\section{References}

1. Kadenbach B, Huttemann M. The subunit composition and function of mammalian cytochrome c oxidase. Mitochondrion. 2015;24:64-76. https://doi.org/10.1016/j.mito.2015.07.002.

2. Maréchal A, Meunier B, Lee D, Orengo C, Rich PR. Yeast cytochrome C oxidase: a model system to study mitochondrial forms of the haem-copper oxidase superfamily. Biochim Biophys Acta. 2012;1817(4):620-8. https://doi. org/10.1016/j.bbabio.2011.08.011.

3. Castresana J, Lubben M, Saraste M, Higgins DG. Evolution of cytochrome oxidase, an enzyme older than atmospheric oxygen. EMBO J. 1994;13(11): 2516-25. https://doi.org/10.1002/j.1460-2075.1994.tb06541.x.

4. Pereira MM, Teixeira M. Proton pathways, ligand binding and dynamics of the catalytic site in haem-copper oxygen reductases: a comparison between the three families. Biochim Biophys Acta. 2004;1655(1-3):340-6. https://doi.org/10.1016/j.bbabio.2003.06.003.

5. Balsa E, Marco R, Perales-Clemente E, Szklarczyk R, Calvo E, Landazuri MO, et al. NDUFA4 is a subunit of complex IV of the mammalian electron transport chain. Cell Metab. 2012;16(3):378-86. https://doi.org/10.1016/j. cmet.2012.07.015.

6. Zong S, Wu M, Gu J, Liu T, Guo R, Yang M. Structure of the intact 14subunit human cytochrome c oxidase. Cell Res. 2018;28(10):1026-34. https:// doi.org/10.1038/s41422-018-0071-1.

7. Hartley AM, Lukoyanova N, Zhang Y, Cabrera-Orefice A, Arnold S, Meunier B, et al. Structure of yeast cytochrome c oxidase in a supercomplex with cytochrome bc1. Nat Struct Mol Biol. 2019;26(1):78-83. https://doi.org/10.1 038/s41594-018-0172-z.

8. Burke PV, Raitt DC, Allen LA, Kellogg EA, Poyton RO. Effects of oxygen concentration on the expression of cytochrome $c$ and cytochrome $c$ oxidase genes in yeast. J Biol Chem. 1997;272(23):14705-12. https://doi. org/10.1074/jbc.272.23.14705.

9. Tsukihara T, Aoyama H, Yamashita E, Tomizaki T, Yamaguchi H, ShinzawaItoh $\mathrm{K}$, et al. The whole structure of the 13-subunit oxidized cytochrome $\mathrm{C}$ oxidase at $2.8 \AA$ A. Science. 1996;272(5265):1136-44. https://doi.org/10.1126/ science. 272.5265 .1136 .

10. Letts JA, Fiedorczuk K, Sazanov LA. The architecture of respiratory supercomplexes. Nature. 2016;537(7622):644-8. https://doi.org/10.1038/nature19774.

11. Gu J, Wu M, Guo R, Yan K, Lei J, Gao N, et al. The architecture of the mammalian respirasome. Nature. 2016;537(7622):639-43. https://doi.org/10.1 038/nature19359.

12. Schagger $H$, Pfeiffer $K$. Supercomplexes in the respiratory chains of yeast and mammalian mitochondria. EMBO J. 2000;19(8):1777-83. https://doi. org/10.1093/emboj/19.8.1777.

13. Rathore S, Berndtsson J, Marin-Buera L, Conrad J, Carroni M, Brzezinski P, et al. Cryo-EM structure of the yeast respiratory supercomplex. Nat Struct Mol Biol. 2019;26(1):50-7. https://doi.org/10.1038/s41594-018-0169-7.

14. Cui TZ, Conte A, Fox JL, Zara V, Winge DR. Modulation of the respiratory supercomplexes in yeast: enhanced formation of cytochrome oxidase increases the stability and abundance of respiratory supercomplexes. J Biol Chem. 2014;289(9):6133-41. https://doi.org/10.1074/jbc.M113.523688.

15. Bazan S, Mileykovskaya E, Mallampalli VK, Heacock P, Sparagna GC, Dowhan W. Cardiolipin-dependent reconstitution of respiratory supercomplexes from purified Saccharomyces cerevisiae complexes III and IV. J Biol Chem. 2013; 288(1):401-11. https://doi.org/10.1074/jbc.M112.425876.

16. Anthony $G$, Reimann A, Kadenbach B. Tissue-specific regulation of bovine heart cytochrome-c oxidase activity by ADP via interaction with subunit Vla. Proc Natl Acad Sci USA. 1993;90(5):1652-6. https://doi.org/10.1073/pnas.90. 5.1652.

17. Fontanesi F, Soto IC, Barrientos A. Cytochrome c oxidase biogenesis: new levels of regulation. IUBMB Life. 2008;60(9):557-68. https://doi.org/10.1002/ iub.86. 
18. Taanman JW, Capaldi RA. Subunit Vla of yeast cytochrome c oxidase is not necessary for assembly of the enzyme complex but modulates the enzyme activity. Isolation and characterization of the nuclear-coded gene. J Biol Chem. 1993;268(25):18754-61. https://doi.org/10.1016/S0021-9258(17)4 6694-4.

19. Vukotic M, Oeljeklaus S, Wiese S, Vogtle FN, Meisinger C, Meyer HE, et al. Rcf1 mediates cytochrome oxidase assembly and respirasome formation revealing heterogeneity of the enzyme complex. Cell Metab. 2012;15(3): 336-47. https://doi.org/10.1016/j.cmet.2012.01.016.

20. Taanman JW, Turina P, Capaldi RA. Regulation of cytochrome c oxidase by interaction of ATP at two binding sites, one on subunit Vla. Biochemistry. 1994;33(39):11833-41. https://doi.org/10.1021/bi00205a020.

21. Warschawski DE, Arnold AA, Beaugrand M, Gravel A, Chartrand E, Marcotte I. Choosing membrane mimetics for NMR structural studies of transmembrane proteins. Biochim Biophys Acta. 2011;1808(8):1957-74. https://doi.org/10.1016/j.bbamem.2011.03.016.

22. Pervushin K, Riek R, Wider G, Wuthrich K. Attenuated T2 relaxation by mutual cancellation of dipole-dipole coupling and chemical shift anisotropy indicates an avenue to NMR structures of very large biological macromolecules in solution. Proc Natl Acad Sci USA. 1997;94(23):12366-71. https://doi.org/10.1073/pnas.94.23.12366.

23. Rehm T, Huber R, Holak TA. Application of NMR in structural proteomics: screening for proteins amenable to structural analysis. Structure. 2002;10(12): 1613-8. https://doi.org/10.1016/S0969-2126(02)00894-8.

24. Wishart DS, Sykes BD, Richards FM. The chemical shift index: a fast and simple method for the assignment of protein secondary structure through NMR spectroscopy. Biochemistry. 1992;31(6):1647-51. https://doi.org/10.1 021/bi00121a010.

25. Zwahlen C, Legault P, Vincent SJF, Greenblatt J, Konrat R, Kay LE. Methods for measurement of intermolecular NOEs by multinuclear NMR spectroscopy: application to a bacteriophage $\lambda$ N-peptide/boxB RNA complex. J Am Chem Soc. 1997;119(29):6711-21. https://doi.org/10.1021/ja 970224q.

26. Brünger AT, Adams PD, Clore GM, DeLano WL, Gros P, Grosse-Kunstleve RW, et al. Crystallography \& NMR system: a new software suite for macromolecular structure determination. Acta Crystallogr D Biol Crystallogr. 1998;54(Pt 5):905-21. https://doi.org/10.1107/S0907444998003254.

27. Hartley AM, Meunier B, Pinotsis N, Marechal A. Rcf2 revealed in cryo-EM structures of hypoxic isoforms of mature mitochondrial III-IV supercomplexes. Proc Natl Acad Sci USA. 2020;117(17):9329-37. https://doi. org/10.1073/pnas.1920612117.

28. Shinzawa-Itoh K, Sugimura T, Misaki T, Tadehara Y, Yamamoto S, Hanada M, et al. Monomeric structure of an active form of bovine cytochrome $\mathrm{c}$ oxidase. Proc Natl Acad Sci USA. 2019;116(40):19945-51. https://doi.org/10.1 073/pnas.1907183116.

29. Strogolova V, Furness A, Robb-McGrath M, Garlich J, Stuart RA. Rcf1 and Rcf2, members of the hypoxia-induced gene 1 protein family, are critical components of the mitochondrial cytochrome bc1-cytochrome c oxidase supercomplex. Mol Cell Biol. 2012;32(8):1363-73. https://doi.org/10.1128/ MCB.06369-11.

30. Dawitz H, Schäfer J, Schaart JM, Magits W, Brzezinski P, Ott M. Rcf1 Modulates Cytochrome c Oxidase Activity Especially Under EnergyDemanding Conditions. Front. Physiol. 2020;10(1555). https://doi.org/10.33 89/fphys.2019.01555

31. Zhou $S$, Pettersson $P$, Huang J, Brzezinski $P$, Pomès $R$, Mäler $L$, et al. NMR structure and dynamics studies of yeast respiratory supercomplex factor 2 Structure. 2021;29(3):275-83.e4

32. Schagger H. Respiratory chain supercomplexes. IUBMB Life. 2001;52(3-5): 119-28. https://doi.org/10.1080/15216540152845911.

33. Ferguson-Miller S, Brautigan DL, Margoliash E. Correlation of the kinetics of electron transfer activity of various eukaryotic cytochromes c with binding to mitochondrial cytochrome c oxidase. J Biol Chem. 1976;251(4):1104-15. https://doi.org/10.1016/S0021-9258(17)33807-3.

34. Arnold S, Kadenbach B. Cell respiration is controlled by ATP, an allosteric inhibitor of cytochrome-c oxidase. Eur J Biochem. 1997;249(1):350-4. https:// doi.org/10.1111/j.1432-1033.1997.t01-1-00350.x.

35. Dodia R, Meunier B, Kay CW, Rich PR. Comparisons of subunit $5 A$ and $5 B$ isoenzymes of yeast cytochrome c oxidase. Biochem J. 2014;464(3):335-42. https://doi.org/10.1042/BJ20140732.

36. Dethmers JK, Ferguson-Miller S, Margoliash E. Comparison of yeast and beef cytochrome c oxidases. Kinetics and binding of horse, fungal, and Euglena cytochromes c. J Biol Chem. 1979;254(23):11973-81. https://doi.org/10.1016/ S0021-9258(19)86413-X.

37. Patriarca A, Eliseo T, Sinibaldi F, Piro MC, Melis R, Paci M, et al. ATP acts as a regulatory effector in modulating structural transitions of cytochrome $\mathrm{C}$ : implications for apoptotic activity. Biochemistry. 2009;48(15):3279-87. https://doi.org/10.1021/bi801837e.

38. Sinibaldi F, Droghetti E, Polticelli F, Piro MC, Di Pierro D, Ferri T, et al. The effects of ATP and sodium chloride on the cytochrome c-cardiolipin interaction: The contrasting behavior of the horse heart and yeast proteins. J Inorg Biochem. 2011;105(11):1365-72. https://doi.org/10.1016/j.jinorgbio.2011.07.022.

39. Williamson MP. Using chemical shift perturbation to characterise ligand binding. Prog Nucl Magn Reson Spectrosc. 2013;73:1-16. https://doi.org/10.1 016/j.pnmrs.2013.02.001

40. El Yacoubi B, Lyons B, Cruz Y, Reddy R, Nordin B, Agnelli F, et al. The universal $\mathrm{YrdC} /$ Sua5 family is required for the formation of threonylcarbamoyladenosine in tRNA. Nucleic Acids Res. 2009;37(9):2894909. https://doi.org/10.1093/nar/gkp152.

41. Harris KA, Bobay BG, Sarachan KL, Sims AF, Bilbille Y, Deutsch C, et al. NMRbased structural analysis of threonylcarbamoyl-AMP synthase and its substrate interactions. J Biol Chem. 2015;290(33):20032-43. https://doi.org/1 0.1074/jbc.M114.631242.

42. Shimada S, Shinzawa-Itoh K, Baba J, Aoe S, Shimada A, Yamashita E, et al. Complex structure of cytochrome c-cytochrome c oxidase reveals a novel protein-protein interaction mode. EMBO J. 2017;36(3):291-300. https://doi. org/10.15252/embj.201695021.

43. Scharlau M, Geren L, Zhen EY, Ma L, Rajagukguk R, Ferguson-Miller S, et al. Definition of the interaction domain and electron transfer route between cytochrome c and cytochrome oxidase. Biochemistry. 2019;58(40):4125-35. https://doi.org/10.1021/acs.biochem.9b00646.

44. From AH, Zimmer SD, Michurski SP, Mohanakrishnan P, Ulstad VK, Thoma WJ, et al. Regulation of the oxidative phosphorylation rate in the intact cell. Biochemistry. 1990;29(15):3731-43. https://doi.org/10.1021/bi00467a020.

45. Nguyen PTM, Ishiwata-Kimata Y, Kimata Y. Monitoring ADP/ATP ratio in yeast cells using the fluorescent-protein reporter PercevalHR. Biosci Biotechnol Biochem. 2019;83(5):824-8. https://doi.org/10.1080/09168451.201 9.1574204 .

46. Zhou S, Pettersson P, Huang J, Sjöholm J, Sjöstrand D, Pomès R, et al. Solution NMR structure of yeast Rcf1, a protein involved in respiratory supercomplex formation. Proc Natl Acad Sci USA. 2018;115(12):3048-53. https://doi.org/10.1073/pnas.1712061115.

47. Zhou S, Pettersson P, Brzezinski P, Ädelroth P, Mäler L. NMR study of Rcf2 reveals an unusual dimeric topology in detergent micelles. ChemBiochem. 2018;19(5):444-7. https://doi.org/10.1002/cbic.201700664.

48. Golovanov AP, Hautbergue GM, Wilson SA, Lian LY. A simple method for improving protein solubility and long-term stability. J Am Chem Soc. 2004; 126(29):8933-9. https://doi.org/10.1021/ja049297h.

49. Vranken WF, Boucher W, Stevens TJ, Fogh RH, Pajon A, Llinas M, et al. The CCPN data model for NMR spectroscopy: development of a software pipeline. Proteins. 2005;59(4):687-96. https://doi.org/10.1002/prot.20449.

50. Salzmann M, Pervushin K, Wider G, Senn H, Wuthrich K. TROSY in tripleresonance experiments: new perspectives for sequential NMR assignment of large proteins. Proc Natl Acad Sci USA. 1998;95(23):13585-90. https://doi. org/10.1073/pnas.95.23.13585.

51. Riek R, Wider G, Pervushin K, Wuthrich K. Polarization transfer by crosscorrelated relaxation in solution NMR with very large molecules. Proc Natl Acad Sci USA. 1999;96(9):4918-23. https://doi.org/10.1073/pnas.96.9.4918.

52. Bax A. Multidimensional nuclear magnetic resonance methods for protein studies. Curr Opin Struct Biol. 1994;4(5):738-44. https://doi.org/10.1016/ S0959-440X(94)90173-2.

53. Bax A, Clore GM, Gronenborn AM. 'H- 'H correlation via isotropic mixing of 13C magnetization, a new three-dimensional approach for assigning $\mathrm{H}$ and 13C spectra of 13C-enriched proteins. J Magn Res. 1990;88:425-31.

54. Grzesiek S, Anglister J, Bax A. Correlation of backbone amide and aliphatic side-chain resonances in 13C/15N-enriched proteins by isotropic mixing of 13C magnetization. J Magn Res Series B. 1993;101(1):114-9. https://doi.org/1 0.1006/jmrb.1993.1019.

55. Marion D, Driscoll PC, Kay LE, Wingfield PT, Bax A, Gronenborn AM, et al. Overcoming the overlap problem in the assignment of $1 \mathrm{H}$ NMR spectra of larger proteins by use of three-dimensional heteronuclear $1 \mathrm{H}-15 \mathrm{~N}$ Hartmann-Hahn-multiple quantum coherence and nuclear Overhauser- 
multiple quantum coherence spectroscopy: application to interleukin 1 beta. Biochemistry. 1989;28(15):6150-6. https://doi.org/10.1021/bi00441a004.

56. Rossi P, Xia Y, Khanra N, Veglia G, Kalodimos CG. (15) N and (13)C-SOFASTHMQC editing enhances 3D-NOESY sensitivity in highly deuterated, selectively [(1)H,(13)C]-labeled proteins. J Biomol NMR. 2016;66(4):259-71. https://doi.org/10.1007/s10858-016-0074-5.

57. Linge JP, Habeck M, Rieping W, Nilges M. ARIA: automated NOE assignment and NMR structure calculation. Bioinformatics. 2003;19(2):315-6. https://doi. org/10.1093/bioinformatics/19.2.315

58. Cheung MS, Maguire ML, Stevens TJ, Broadhurst RW. DANGLE: a Bayesian inferential method for predicting protein backbone dihedral angles and secondary structure. J Magn Res. 2010;202(2):223-33. https://doi.org/10.101 6/j.jmr.2009.11.008

59. Laskowski RA, MacArthur MW, Moss DS, Thornton JM. PROCHECK: a program to check the stereochemical quality of protein structures. J Appl Crystallogr. 1993;26(2):283-91. https://doi.org/10.1107/\$0021889892009944.

60. Pettersen EF, Goddard TD, Huang CC, Couch GS, Greenblatt DM, Meng EC, et al. UCSF Chimera--a visualization system for exploratory research and analysis. J Comput Chem. 2004;25(13):1605-12. https://doi.org/10.1002/jcc.2 0084.

61. Meunier B, Marechal A, Rich PR. Construction of histidine-tagged yeast mitochondrial cytochrome $\mathrm{c}$ oxidase for facile purification of mutant forms. Biochem J. 2012;444(2):199-204. https://doi.org/10.1042/BJ20120116.

62. Dominguez C, Boelens R, Bonvin AM. HADDOCK: a protein-protein docking approach based on biochemical or biophysical information. J Am Chem Soc. 2003;125(7):1731-7. https://doi.org/10.1021/ja026939x.

\section{Publisher's Note}

Springer Nature remains neutral with regard to jurisdictional claims in published maps and institutional affiliations.

Ready to submit your research? Choose BMC and benefit from:

- fast, convenient online submission

- thorough peer review by experienced researchers in your field

- rapid publication on acceptance

- support for research data, including large and complex data types

- gold Open Access which fosters wider collaboration and increased citations

- maximum visibility for your research: over $100 \mathrm{M}$ website views per year

At $\mathrm{BMC}$, research is always in progress.

Learn more biomedcentral.com/submissions 